DOI: https://doi.org/10.15688/jvolsu2.2018.2.1

UDC 81 ' 42

Submitted: 07.05.2018

LBC 81.055 .1

Accepted: 04.06.2018

\title{
TEXT LINGUISTICS IN THE STRUGGLE FOR PRECISION AND COMPREHENSION COVERAGE
}

\author{
Svetlana V. Ionova \\ Pushkin State Russian Language Institute, Moscow, Russia
}

\begin{abstract}
The article deals with the latest tendencies in the development of text linguistics, defines the importance of linguistics being focused to studies of various text types. Having considered the issue of text linguistics status in the $20^{\text {th }}$ and the early $21^{\text {st }}$ centuries the author underlines it that text linguistics should be referred to a socially significant area of knowledge which reflects a great demand for text variations in modern communication practices. It is stated that in a modern text linguistics paradigm the notion of the text embraces both limited and receptive approaches which open ways to text analysis directed "from form to meaning" and "from meaning to form" thus providing opportunities for overcoming the text producer's subjectivity and asymmetry in verbalizing personal ideas. Being a humanitarian field of knowledge text linguistics can't be referred to a science with accurate tools of measurement. However, its latest development is marked with a trend of accuracy and exactness in research procedures, distinguished meta-language, categories and units of studies. In conclusion the author underlines it that the latest trends in social communications present new objects for investigations, and text linguistics with its combinations of research techniques could be efficient in meeting challenges resulted from new text forms appearance.
\end{abstract}

Key words: text, text linguistics, discourse, method, text communication, social communication.

Citation. Ionova S.V. Text Linguistics in the Struggle for Precision and Comprehension Coverage. Vestnik Volgogradskogo gosudarstvennogo universiteta. Seriya 2, Yazykoznanie [Science Journal of Volgograd State University. Linguistics], 2018, vol. 17, no. 2, pp. 6-14. (in Russian). DOI: https://doi.org/10.15688/jvolsu2.2018.2.1

УДК 81 ' 42

Дата поступления статьи: 07.05.2018

ББК 81.055 .1

Дата принятия статьи: 04.06.2018

\section{ЛИНГВИСТИКА ТЕКСТА В СТРЕМЛЕНИИ К ТОЧНОСТИ И ШИРОТЕ}

\section{Светлана Валентиновна Ионова}

Государственный институт русского языка им. А.С. Пушкина, г. Москва, Россия

\footnotetext{
Аннотация. В статье характеризуются современные тенденции развития лингвистики текста, обосновывается важность лингвистического подхода к исследованию текстовых произведений разных типов. Рассматривается проблема определения статуса лингвистики текста в XX и начале XXI века. Лингвистика текста, по мнению автора, представляет собой социально значимую область знания, востребованную практикой с современных социальных коммуникаций. Продемонстрировано, что современное состояние лингвистики 。 ․ текста позволяет соединять узкий и широкий подходы к пониманию текста, проводить анализ в направлении «от формы к смыслу» и «от смысла к форме», преодолевать асимметрию и субъективизм автора при вербализации замысла. Будучи гуманитарной областью знания, лингвистика текста не является точной наукой, но
} 
в истории ее развития отмечается тенденция к точности исследовательских процедур, метаязыка, категориального аппарата, единиц анализа. На примере новых работ в области лингвистики текста показано, что предмет изучения этой науки значительно усложнился. В то же время объединение исследовательских методик теории текста и теории дискурса позволяет сегодня этой науке решать сложные задачи, связанные с описанием и анализом новых текстовых явлений, востребованных практикой.

Ключевые слова: текст, дискурс, лингвистика текста, точные науки, метод, социальная коммуникация, текстовая коммуникация, тенденция развития.

Цитирование. Ионова С. В. Лингвистика текста в стремлении к точности и широте // Вестник Волгоградского государственного университета. Серия 2, Языкознание. - 2018. - T. 17, № 2. - C. 6-14. - DOI: https://doi.org/ 10.15688/jvolsu2.2018.2.1

\section{Введение}

Понятие текста в современной лингвистике распространяется на все знаковые образования, включая в объект изучения визуализированные произведения, произвольно организованные речевые высказывания (например, естественная письменная речь), транслируемые по разным каналам восприятия и направленные на обслуживание разных сфер современной жизни. Давний спор ученых - сторонников узкого и предельно широкого понимания текста - сегодня получает примиряющее решение. Текст как объект изучения в современном языкознания наделяется свойством всеобщности («внетекстовой реальности не существует») [Деррида, 2000, с. 313], способности «определять характер сообщества» [Ellmore, 1992, p. 2], являться «конденсатором культурной памяти» [Лотман, 1996, с. 10], существовать в контексте сверхтекста культуры. В то же время не потерял своей актуальности семиотический подход к исследованию текста как сложного знака, многоканального транслятора смыслов, упорядоченного единства, дающего возможность для изучения внутреннего устройства текстовых произведений разных типов, оптимизации их знаковых возможностей, разработки новых моделей кодирования социально и личностно значимых смыслов.

\section{К постановке проблемы}

Приметой нашего времени стало усиление разнонаправленных тенденций в понимании и изучении текста, которые сегодня не являются антагонистическими, а определяют диалектическое единство природы текста как сложного знакового, социального и культурного феномена. С одной стороны, новые компьютерные технологии позволяют перейти от обмена готовыми текстами к моделированию естественной коммуникации с включением человека в социально-культурный контекст взаимодействия, вследствие чего значительно размываются границы традиционного понимания текста и дискурса. С другой стороны, формирование сетевого текстового пространства, знаковой среды существования человека стимулирует постоянное совершенствование процедур кодирования информации, ее интерпретации и хранения, что определяет важность разработки максимально точных методов анализа текстов, их переработки и хранения. Таким образом, стремление современной лингвистики текста, с одной стороны, к широте - к постановке и решению задач, востребованных социальной практикой, а с другой стороны, к точности процедур описания и воспроизведения информации позволяет выявить новое, не отмеченное ранее качество этой отрасли знания в XXI веке [Ионова, 2012].

\section{Есть такая наука}

И.Р. Гальперин в своей книге «Текст как объект лингвистического исследования» еще в 1980 г. отмечал, что лингвистика текста стала одной из наиболее актуальных проблем отечественной науки [Гальперин, 1981]. Однако традиционный уровневый подход в языкознании предполагал, что прийти к осознанию текста как лингвистического феномена можно только «снизу», от предложения, найдя среди традиционных языковедческих проблем такие, разрешение которых невозможно без выхода за пределы предложения. Наука 3070-х гг. XX в. заложила основы для выделе- 
ния лингвистики текста в самостоятельную дисциплину, имеющую самостоятельный объект и предмет изучения. Вышедший в 1978 г. под редакцией Т.М. Николаевой восьмой выпуск книги «Новое в зарубежной лингвистике», посвященный проблемам лингвистики текста, ознаменовал собой завершение этапа первичной систематизации знаний о тексте и наметил перспективы лингвистики текста как самостоятельной отрасли науки [Демьянков, 2005, с. 35].

К концу XX в. представление о тексте как о линейной последовательности знаков языка, которые позволяют кодировать информацию о многомерном пространстве жизни, получило закрепление во многих определениях (см.: определения текста, предложенные в работах Э. Бенвениста, Р.А. Будагова, Т.М. Николаевой, О.И. Москальской, Л.Н. Мурзина, А.С. Штерн и др.), утверждая первичность подхода к изучению текста в направлении «от формы к смыслу». В многочисленных концепциях текста, рожденных в недрах уровневого описания языковых явлений, предлагаемые модели текстообразования и понимания текста, разработка структурной модели содержания, типологизация речевых произведений, проводимая по разным основаниям, во многом способствовали формированию современных представлений о тексте как сложном, многомерном образовании, точному и непротиворечивому описанию его свойств и особенностей функционирования.

В это же время рассматриваемый феномен стал осмысливаться и в ином направлении - с позиций психолингвистики и когнитивной лингвистики, где процессы текстообразования изучаются в направлении «от смысла к форме» (Н.И. Жинкин, А.А. Леонтьев, А.И. Новиков, Л.В. Сахарный и др.) и на первый план вместо категории связности выходит категория цельности. Как показывают исследования ученых, функционально эти свойства текста являются выражением разных аспектов одной сущности и отражением особенностей право- и левополушарного устройства головного мозга человека [Caхарный, 1991, с. 223].

К концу ХХ в. лингвистика текста обосновывается как социально значимая область знания, востребованная практикой [Дридзе, 1984]. В начале XXI в. текстовые компетенции уже вторгаются в житейский опыт, а научные знания о природе текста - в обыденные представления носителей языка, выступая в качестве интегративного качества личности, показателя развития ее культуры. Под текстовой компетенцией понимается целый комплекс знаний и умений, нацеленных на первичную и вторичную текстовую деятельность: 1) знание действительности, умение отражать ее в слове при текстообразовании и понимать на основе интерпретационной деятельности; 2) умение проявлять свой взгляд на мир, свою творческую индивидуальность в выборе жизненного материала и его отражении в слове; осознание индивидуального авторского стиля; 3) знания о сферах общения, ситуациях, условиях общения и умение учитывать это при текстообразовании и восприятии текста; 4) знание об адресате и умение учитывать фактор адресата в процессе текстовой деятельности; 5) знание языковых ресурсов, умение их отбирать, организовывать в процессе текстовой деятельности [Жеребило, 2011, с. 87].

Вопрос о статусе данной науки сегодня не стоит, он безусловно признается лингвистами. Текст как когнитивная и коммуникативная единица выступает ярким признаком антропоцентризма и одним из основных объектов исследования в антропоцентрическом языкознании [Кубрякова, 1995, с. 148]. Тезис М.М. Бахтина «текст - первичная данность (реальность) и исходная точка всякой гуманитарной дисциплины» [Бахтин, 1986, с. 308] не только приобрел актуальный смысл, но и мотивировал переосмысление предмета самого языковедения на современном этапе [Филиппов, 2003, с. 9].

\section{«Неточных» наук быть не может}

Лингвистика текста является одной из важнейших отраслей языкознания, позволяющих изучать разные способы представления знания и формирования смысла в речевых произведениях, а также механизмы восприятия и понимания заданного содержания. В тексте находят применение и реализацию все ресурсы языковой системы, все средства и способы выражения содержания. Однако сложность внутреннего устройства текста, 
многоаспектность его содержания, недостаточно определенный статус единиц и категорий, отсутствие структурных методов исследования текстовых произведений на начальных этапах развития этой отрасли языкознания не позволяли в достаточной мере формализовать лингвистическое описание анализируемых текстов, выявить специфические для лингвистики подходы их исследования, унифицировать метаязык описания и анализа. Нередко в рамках лингвистического изучения текста происходило заимствование методик смежных наук: литературоведческого анализа, контент-анализа, герменевтической интерпретации и др. Все это создавало впечатление отсутствия точности и определенности в исследовании текстовых произведений, субъективности результатов, получаемых в ходе их анализа.

Вероятно, именно данные причины вызвали дискуссию о лингвистическом статусе текста, о возможности выделения текстолингвистики в отдельную область знания. В работах профессора А.Т. Кривоносова данный период в развитии лингвистики текста называется «очередным этапом лингвистических заблуждений» [Кривоносов, 1986, с. 36], сама наука - «описательно-спекулятивной», пользующейся дилетантскими методами [Кривоносов, 1986, с. 36]. Подобные дискуссии в науке последней трети ХХ в. по сути сводились к «старому спору - в каком стане быть лингвистике?» [Будагов, 1972, с. 402]: точных наук или гуманитарных.

Высказывая мнение по поводу научного статуса языкознания в целом, Р.А. Будагов писал: «В подобном представлении, чтобы стать точной, наука должна лишиться своего гуманитарного аспекта. <..> Защитник приведенного тезиса даже не подозревает, что любая гуманитарная наука может весьма успешно развиваться, вовсе не лишаясь своего гуманитарного характера» [Будагов, 1972, c. 403]; «Каждая наука оперирует своим понятием точности, причем в пределах каждой, отдельно взятой науки подобная точность может быть максимальной даже независимо от того, одинаково или неодинаково истолковывают разные ученые основы данной науки. Поясним сказанное. Едва ли кто-нибудь станет сомневаться в точности теории относи- тельности, сыгравшей выдающуюся роль в физике XX столетия» [Будагов, 1972, с. 403]. Рассуждения ученого в значительной степени можно отнести к определению характеристик лингвистики текста.

В продолжение высказывания А.Р. Будагова отметим, что, несмотря на фундаментальный принцип познания как достижения определенности, гносеологически освоение мира и представление о нем опосредуется механизмами аппроксимации, под которой принято понимать «метод сознательного упрощения “слишком точного" теоретического знания с целью привести его в соответствие с потребностями и возможностями практики» [Левин, 2010]. Как гуманитарная область знания лингвистика текста в значительной степени антропоцентрична, несводима к абстрактным строгим структурным моделям, характерным, например, для единиц фонетического уровня языка. В этой области знания во многом пересматриваются традиционные подходы к изучению «укрупненных» лингвистических единиц: любой текст - это произведение человеческой деятельности (текстовой, познавательной, эмоциональной); человек всегда пристрастно отражает действительность; внутреннее устройство текста позволяет реализовать этот пристрастный взгляд на мир. Однако поскольку изображения объекта или представления о нем не могут быть истинными как таковые, вне соответствия, совпадения с отражаемым, то признается, что при определении истинности существенным является акцентирование внимания на отличии реальности от представления, изображения. Таким образом, лингвистика текста с самого начала имеет дело со смысловым сдвигом, в то же время критерии точности в ней не «расшатываются» даже тогда, когда «основы данной науки различно истолковываются в различных теоретических школах» [Будагов, 1972, с. 403].

Современный этап развития этой отрасли языкознания демонстрирует объективное движение к разработке более точных методов и подходов к анализу текстовых произведений, к установлению лингвистических признаков, позволяющих с достаточной степенью определенности интерпретировать их содержание и смысл, к конкретизации и детализа- 
ции описания текста как сложного и многоаспектного явления с опорой на языковые единицы. Ярким примером подобных исследований стала разработка важнейших категорий текста и их реализаций в разных коммуникативных контекстах и типах речевых произведений.

Наиболее сложным вопросом, связанным с точностью воспроизведения и понимания смысла текста, является дифференциация понятий «содержание» и «смысл», изучение понятия смысловой доминанты. Введенный К. Харди термин «смысловая доминанта» применяется для описания смысловых процессов восприятия текста. В работах психолингвистов конца XX в. получают определение такие термины, как «смысловая веха», «опорная точка», «креативный аттрактор» текста, которые понимаются как поля, смысловые области, формирующиеся вокруг доминантных лексем [Герман, Пищальникова, 1999; Залевская, 2001]. В контексте синергетической концепции текста смысловые доминанты текста рассматриваются в качестве динамических единиц: смысловая «зона гармонизации симметрии и асимметрии, организации и самоорганизации текста, зона притяжения всех элементов текста, позволяющая ему существовать как целому, одновременно допуская возможность его прерывания в состоянии относительной стабильности и перехода к иному состоянию» [Герман, Пищальникова, 1999, с. 55].

Применение разработанных принципов выявления смысловых доминант к анализу научных текстов представлено в работе Н.К. Рябцевой «Название как доминантный компонент научного текста: русско-английские межъязыковые несоответствия», включенной в данный номер журнала: на основе сопоставления доминирующих смыслов русскоязычных названий научных статей и их переводов на английский язык продемонстрированы способы смещения смысловой доминанты, нарушения смысловой точности при воспроизведении интенций и целей автора, стилевых особенностей оригинала.

В центре научных интересов лингвистов в XXI в. остается исследование художественного текста, воплощающего в себе все языковые и речевые возможности автора при реализации замысла. В отличие от начальных этапов развития лингвистики текста, сегодня художественный текст рассматривается как сложное, многоуровневое речевое произведение, которое, однако, имеет конститутивные признаки, свойственные любым другим текстам, и может анализироваться с применением разработанных для них объективных методов лингвистического анализа. Это дает возможность рассматривать в качестве предмета исследования в том числе экстралингвистические категории произведения, которые ранее в лингвистике не изучались. Так, в центре статьи Н.А. Фатеевой, вошедшей в данный номер журнала, находятся вопросы языковой креативности автора поэтического текста, которая исследуется с применением лингвистического анализа грамматических единиц как маркеров текстовой деятельности автора. Демонстрируется, что продуктивность и парадигматичность авторских новообразований тесно связана с моделями языковой деривации, а их использование дает возможность каждому пишущему реализовать себя в индивидуально-авторских формах.

Точность языка художественной литературы - явление особое, обладающее своими критериями. Анализ формы текста, совершенствование методов описания здесь должно стремиться к полноте и структурной определенности, хотя однозначность интерпретации авторского смысла зачастую невозможна, нефункциональна, не соответствуюет типу дискурса. Данный аспект художественного текста требует от исследователя применения комплекса методов в рамках антропоцентрической методологии в языкознании, а для адресата составляет отдельный вид текстовой деятельности: «Чтение книг, то есть их дешифровка, - это напряженная работа, которой надо специально обучать, но зато получаемые сведения становятся частью сознания и мировоззрения личности» [Костомаров, 2010, p. 145].

\section{Широта социальных коммуникаций и текст}

Известно, что верная теория всегда порождает мысли, простирающиеся к приращению общественной пользы» (М.В. Ломоносов). Акцентирование внимания ученых на взаимо- 
связи языка и жизни - это не просто метафо$\mathrm{pa}$, а основной принцип научной деятельности, востребованный современной практикой. Практическая значимость речевых произведений как объектов лингвистики текста состоит в обеспечении текстовой коммуникации в обществе, под которой понимается «обмен действиями порождения и интерпретации текстов, в ходе которой выясняется, способны или не способны люди понимать друг друга» [Дридзе, 1984, с. 145].

Тексты сопровождают процессы коммуникации, информационных обменов, которые сегодня уже не могут быть сведены к трехэлементной схеме К. Шеннона (автор - сообщение - получатель). Они обеспечивают биологическое и социальное существование человека, его ориентацию в информационной среде, поэтому такие практические умения, как понимание содержания текста, оформление в виде документа, пересказ с иными целями, конспектирование или тезисное изложение, составление резюме и т. д., - входят в число формируемых умений и навыков.

Речевые произведения сегодня приобретают ценность не только с позиций современной теории языка, но и в прикладном аспекте, в плане реализации их в междисциплинарных областях: в сферах издательской деятельности и документалистики; электронной коммуникации и компьютерного дела; массовой коммуникации и информационного менеджмента; в юридической практике и автороведении; психодиагностической и лингвотерапевтической сферах; корпусной лингвистике и др.

Значительное расширение сферы функционирования текстов обусловило появление в терминологическом базисе этой науки понятия «дискурс», которое было призвано акцентировать внимание исследователей на динамическом аспекте текстообразования, его включенности в жизнь [Арутюнова, 1990]. В современной лингвистике накоплен багаж знаний, связанных с дискурсивной теорией и практикой: выработаны функциональные определения дискурса, охарактеризованы его типичные элементы, разработаны типологии дискурсов по разным основаниям; описаны многочисленные дискурсивные практики в разных сферах межличностной и институциональной коммуникации.

Одним из важных вопросов, касающихся современной теории дискурса, является соотношение этого понятия с понятием «текст». Несмотря на значительную теоретическую разработанность этого вопроса, он остается открытым в связи с возникновением новых сфер коммуникации, требующих внесения корректив в существующие представления о речевой и текстовой коммуникации (например, развитие сферы компьютерной коммуникации, сетевого общения со свойственной им устно-письменной формой фиксации информации, изменением форм существования текста, имитацией непосредственного общения).

Следуя принципу «любой текст может быть осуществлен в любой форме» [Костомаров, 2010, p. 143], автор вправе самостоятельно выбирать форму воплощения своих интенций. При этом решающее значение в выборе адекватной, уместной и эффективной формы их выражения приобретают дискурсивные условия осуществления взаимодействия между автором и адресатом. Таким образом, обращение к теоретическим вопросам лингвистики текста неразрывно связано с изучением вопросов теории дискурса. Подобный подход представлен, например, в статье Е.Ф. Кирова «Текст и дискурс в семиотическом соотношении», включенной в данный номер журнала: автор утверждает, что текст представляет собой знак дискурса и обязательно существует в одной из коммуникативных позиций - сильной, слабой или сверхслабой, а предельным совпадением текста и дискурса является перформативный дискурс и текст.

Проблема зависимости форм текстов от дискурсивных сфер их функционирования сегодня приобретает особую актуальность, поскольку современная жизнь предоставляет все больше возможностей для формирования новых информационных и коммуникативных пространств, в которых образуются новые, ранее не востребованные типы текстов. Исследуя сферу гостиничного бизнеса, О.С. Иссерс (см. ее статью в данном номере журнала) пришла к выводу о том, что в его дискурсивном пространстве не просто апробируются новые формы текстов, а складывается це- 
лая система новых жанров: путеводитель по отелю, тексты экологической направленности, «жанры заботыл; существующие жанры обогащаются новым содержанием, приобретая коммуникативно-прагматическую специфику в новом дискурсе (тексть буклетов и иных информационных материалов, размещаемых в номере отеля), иллюстрируя тезис о том, что дискурсивные практики всегда функционируют в диалектическом взаимодействии с другими социальными практиками.

Совокупность признаков текста, которые обеспечивают относительную независимость от ситуации общения и его воспроизводимость, позволяет охарактеризовать текстовое произведение как «упакованную коммуникацию» [Дымарский, 2001, с. 35], в которой в снятом виде, при помощи знаков языка представлены все основные параметры коммуникативной ситуации (образ автора, образ адресата, характер сообщения, языковой код, характер контакта между автором и потенциальным адресатом, отношение к контексту других сообщений). Таким образом, текст вне дискурсивных условий способен отражать коммуникативные стратегии и тактики участников коммуникации, изучение которых требует применения специальных лингвистических подходов к анализу материала.

Один из таких подходов, имеющих социально значимые цели, предполагает разработку комплекса лингвистических приемов, направленных на выявление скрытой прагматики текста, состоящей в неосознанном использовании автором специальных языковых и речевых средств, которые предназначены для воздействия на читателя (см. статью Г.Г. Матвеевой и И.А. Зюбиной в данном номере журнала). Ученые отмечают зависимость организации письменного текста от выбора жанра (научный, научно-популярный и учебный), от ориентации автора на единичного или массового адресата, от вида (эмотивного или конативного) планируемого речевого воздействия, от стратегии скрытого воздействия и экстралингвистических факторов. Таким образом, даже прямо не вербализуемые коммуникативные стратегии и тактики автора текста сегодня получают достаточно точное лингвистическое описание, основанное на применении объективных методов лингвистического анализа.

В социальном контексте процессы текстообразования приобретают черты сознательного действия автора по «конструированию смыслов» [Дридзе, 1984, с. 42-43]. В указанном аспекте сегодня изучается и такое сложное явление вербального взаимодействия, как эмоционально опосредованная коммуникация. Осознанность и контролируемость в демонстрации эмоций может осуществляться с разными стратегическими целями: воздействия на окружающих, демонстрации лояльности, доброжелательности, предупреждения возможного конфликта, - где она выполняет социальную функцию: повлиять на восприятие собеседником ситуации и на ее понимание [Ларина, 2003, с. 166].

В силу динамичности эмоциональных процессов и сложной кластерной природы эмоций их непосредственное проявление в дискурсивных условиях не всегда адекватно переводится в вербальные формы. В связи с этим ученые все чаще обращаются к традиционному материалу - текстам сложной структуры, художественным текстам, в которых зафиксированы эмоциональные явления в их многоаспектности. Так, в работах Л.А. Калимуллиной отрабатываются формы анализа и описания типичных моделей эмоционально опосредованных ситуаций страха, включающих такие частные признаки, как 'предметность эмочии', 'внутренняя / внешняя причинная обусловленность', 'связь с интеллектуальной и волевой сферами' и др.; 'временная актуализованность (эпизодичность) / вневременность (стабильность)', 'статичность / динамичность', ‘фазисность протекания' и др. [Калимуллина, 2002]. Параметризация эмоциональных коммуникативных ситуаций осуществляется на основе учета дискурсивных условий, однако форма воплощения эмотивной информации здесь текстовая, позволяющая использовать комплекс дискурсивных методов, а также методик текстового анализа.

\section{Выводы}

Известно, что толкование эмпирических фактов только тогда считается научным, ког- 
да это толкование становится объективным и получает возможность стать общепризнанным. Современная лингвистика текста в ее стремлении к точности метаязыка, единиц описания, категорий, исследовательских методик за короткий промежуток времени достигла значительных результатов и по праву считается сегодня объяснительной отраслью науки, достижения которой востребованы в практике социальных коммуникаций и других прикладных сферах жизнедеятельности человека.

Свидетельством значительного прогресса в изучении процессов текстообразования, текстопреобразования и понимания текста является объективная готовность этой науки, обогащенной теорией дискурса, изучать самые сложные знаковые явления - от текстовпримитивов [Сахарный, 1991] как моделей свернутой формы существования смысла до текста как «абсолютной тотальности» [Деррида, 2000]; исследовать многообразные семантические и прагматические стратегии перевода события в текст; фиксировать бесконечно вариативные способы вербализации информации о действительности; объективировать субъективные модели коммуникативных ситуаций; преодолевать неизбежную асимметрию реальной и отраженной в тексте информации.

\section{СПИСОК ЛИТЕРАТУРЫ}

Арутюнова Н. Д., 1990. Дискурс // Лингвистический энциклопедический словарь / гл. ред. В. Н. Ярцева. М. : Сов. энцикл. С. 136-137.

Бахтин М. М., 1986. Эстетика словесного творчества. М. : Искусство. 445 с.

Будагов Р. А., 1972. О предмете языкознания // Известия АН СССР. Отделение литературы и языка. Т. XXXI, вып. 5. С. 401-412.

Гальперин И. Р., 1981. Текст как объект лингвистического исследования. М. : Наука. 138 c.

Герман И. А., Пищальникова В. А., 1999. Введение в лингвосинергетику. Барнаул : Изд-во Алт. ун-та. $130 \mathrm{c}$.

Демьянков В. 3., 2005. Текст и дискурс как термины и как слова обыденного языка // Язык. Личность. Текст : сб. ст. к 70-летию Т.М. Николаевой / отв. ред. В. Н. Топоров. М. : Языки славянских культур. С. 34-55.

Деррида Ж., 2000. О грамматологии. М. : Ad Marginem. $511 \mathrm{c}$.
Дридзе Т. М., 1984. Текстовая деятельность в структуре социальной коммуникации: проблемы семиосоциопсихологии. М. : Наука. 268 с.

Дымарский М. Я., 2001. Проблемы текстообразования и художественный текст: на материале русской прозы XIX-XX вв. М. : Эдиториал УРCC. $328 \mathrm{c}$.

Жеребило Т. В., 2011. Термины и понятия: методы исследования и анализа текста : слов.-справ. Назрань : Пилигрим. 108 c.

Залевская А. А., 2001. Текст и его понимание. Тверь : Изд-во ТГУ. $178 \mathrm{c.}$

Ионова С. В., 2012. Направления современных исследований текста // Россия лингвистическая: научные направления и школы Волгограда : коллектив. моногр. Волгоград : Волгогр. науч. изд-во. С. 195-212.

Калимуллина Л. А., 2002. Фреймовый подход к анализу эмотивной лексики в художественном тексте // Реальность, язык и сознание : Междунар. межвуз. сб. науч. тр. Тамбов : Изд-во Тамб. гос. ун-та. С. 328-331.

Костомаров В. Г., 2010. Дисплейный текст как форма сетевого общения // Russian Language Journal. Iss. 60. Divergent Thinking: Prospectives on the Language Enterprise in the $21^{\text {st }}$ Century. P. 141-147.

Кривоносов А. Т., 1986. «Лингвистика текста» и исследование взаимоотношений языка и мышления // Вопросы языкознания. № 6. C. 23-37.

Кубрякова Е. С., 1995. Эволюция лингвистических идей во второй половине XX века (опыт парадигмального анализа) // Язык и наука конца ХХ века : сб. ст. М. : ИЯ РАН, 1995. С. 144-238.

Ларина Т. В., 2003. Категория вежливости в английской и русской коммуникативных культурах. М. : Изд-во РУДН. 316 с.

Левин Г. Д., 2010. Аппроксимация // Новая философская энциклопедия : в 4 т. М. : Мысль. Т. 1. URL: https://iphlib.ru/greenstone3/library/ collection/newphilenc/document/HASH6747 acdc7baf38e6cfee67.

Лотман Ю. М., 1996. Внутри мыслящих миров. Человек - текст - семиосфера - история. М. : Школа «Языки русской культуры». 464 c.

Сахарный Л. В., 1991. Тексты-примитивы и закономерности их порождения // Человеческий фактор в языке: язык и порождение речи. М. : Наука. С. 221-237.

Филлипов К. А., 2003. Лингвистика текста : курс лекций. СПб. : Изд-во СПб. ун-та. 336 с.

Ellmore Terry R., 1992. Mass Media Dictionary. Special edition. National Texbook company. Lincolnwood, Illinois, USA : National Texbook company. $668 \mathrm{p}$. 


\section{REFERENCES}

Arutyunova N.D., 1990. Discourse. Yartseva V.N., ed. Linguistic Encyclopedic Dictionary. Moscow, Sovetskaya entsiklopediya Publ., pp. 136-137.

Bakhtin M.M., 1986. Aesthetics of verbal creativity. Moscow, Iskusstvo Publ. 445 p.

Budagov R.A., 1972. On the subject of linguistics. Izvestiya AN SSSR. Otdelenie literatury $i$ yazyka, vol. XXXI, iss. 5, pp. 401-412.

Galperin I.R., 1981. Text as an object of linguistic research. Moscow, Nauka Publ. 138 p.

German I.A., Pishchalnikova V.A., 1999. Introduction to linguosynergetics. Barnaul, Izd-vo Alt. un-ta. $130 \mathrm{p}$.

Demyankov V.Z., 2005. Text and discourse as terms and as words of everyday language. Toporov V.N., ed. Yazyk. Lichnost. Tekst: sb. st. $k$ 70-letiyu T.M. Nikolaevoy. Moscow, Yazyki slavyanskikh kultur, pp. 34-55.

Derrida J., 2000. About grammatology. Moscow, Ad Marginem Publ. 511 p.

Dridze T.M., 1985. Text activity in the structure of social communication: the problems of semiosociopsychology. Moscow, Nauka Publ. 268 p.

Dymarskiy M.Ya., 2001. Problems of text formation and fiction text: based on the Russian prose of the $19^{\text {th }}-20^{\text {th }} \mathrm{cc}$. Moscow, Editorial URSS Publ. $328 \mathrm{p}$.

Zherebilo T.V., 2011. Terms and concepts: methods of research and analysis of text. Dictionary and reference book. Nazran, Piligrim Publ. 108 p.

Zalevskaya A.A., 2001. Text and its understanding. Tver, Izd-vo TGU. $178 \mathrm{p}$.

Ionova S.V., 2012. Area of modern text research. Rossiya lingvisticheskaya: nauchnye napravleniya $i$ shkoly Volgograda: kollektivnaya monografiya. Volgograd, Volgogradskoe nauchnoe izd-vo, pp. 195-212.
Kalimullina L.A., 2002. A frame approach to the analysis of emotive vocabulary in a fiction text. Realnost, yazyk i soznanie: Mezhdunar. mezhvuz. sb. nauch. tr. Tambov, Izd-vo TGU, pp. 328-331.

Kostomarov V.G., 2010. Display text as a form of network communication. Russian Language Journal, vol. 60: Divergent Thinking: Prospectives on the Language Enterprise in the $21^{\text {st }}$ Century, pp. 141-147.

Krivonosov A.T., 1986. Text linguistics and the study of the relationship between language and thinking. Voprosy yazykoznaniya [Topics in the Study of Language], no. 6, pp. 23-37.

Kubryakova E.S., 1995. Evolution of linguistic ideas in the second half of the $20^{\text {th }}$ century (experience of paradigm analysis). Yazyk $i$ nauka kontsa XX veka: sb. st. Moscow, IYa RAN Publ., pp. 144-238.

Larina T.V., 2003. The category of politeness in English and Russian communicative cultures. Moscow, Izd-vo RUDN. 316 p.

Levin G.D., 2010. Approximation. New philosophical encyclopedia: in 4 vols. Vol. 1. Moscow, Mysl Publ. URL: https://iphlib.ru/greenstone3/library/ collection/newphilenc/document/HASH6747 acdc7baf38e6cfee67.

Lotman Yu.M., 1996. Inside of the thinking worlds. Man - text - semiosphere - history. Moscow, Yazyki russkoy kultury Publ. $464 \mathrm{p}$.

Sakharnyy L.V., 1991. Texts-primitives and patterns of their generation. The human factor in language: language and the generation of speech. Moscow, Nauka Publ., pp. 221-237.

Fillipov K.A., 2003. Text linguistics: a course of lectures. Saint Petersburg, Izd-vo S.-Peterburgskogo un-ta. $336 \mathrm{p}$.

Eillmore T.R., 1992. Mass Media Dictionary. Special edition. Lincolnwood, Illinois, USA, National Texbook company. $668 \mathrm{p}$.

\section{Information about the Author}

Svetlana V. Ionova, Doctor of Sciences (Philology), Professor, Department of General and Russian Linguistics, Pushkin State Russian Language Institute, Akademika Volgina St., 6, 117485 Moscow, Russia, sionova@mail.ru,https://orcid.org/0000-0001-6361-741X

\section{Информация об авторе}

Светлана Валентиновна Ионова, доктор филологических наук, профессор кафедры общего и русского языкознания, Государственный институт русского языка им. А.С. Пушкина, ул. Академика Волгина, 6, 117485 г. Москва, Россия, sionova@mail.ru, https://orcid.org/0000-0001-6361-741X 